\title{
Shoot Length Distribution and Its Relation to Yield of Alternate-bearing Pistachio Trees
}

\author{
M.T. Stevenson \\ Biologically Integrated Orchard Systems Project, Community Alliance with Family Farmers, P.O. Box \\ 363, Davis, CA 95617
}

\author{
K.A. Shackel and L. Ferguson \\ Department of Pomology, University of California Davis, Davis, CA 95616-8683
}

Additional Index words. Pistacia vera, shoot extension, shoot growth, branching, bud abscission, biennial bearing, masting

\begin{abstract}
Pistachio (Pistacia vera L.) is known to strongly exhibit alternate bearing. Over 19,500 individual shoots were measured on eight alternate bearing 'Kerman' pistachio trees on $P$. atlantica Desf. rootstock. Average length of "on" year $(5.4 \mathrm{~cm})$ and "off" year new shoots $(5.6 \mathrm{~cm})$ were not significantly different. New shoot length distribution was skewed toward the shorter length categories, with a mode of 2 and $4 \mathrm{~cm}$ in "on" and "off" trees respectively. These results contrast with previous studies which have shown that "on" year new shoots of pistachio are much longer than "off" year new shoots. There were about twice as many "on" year new shoots in the 18 to $30 \mathrm{~cm}$ class as compared to "off" new shoots, and fruiting wood length was associated positively with fruit number. However, $\approx \mathbf{8 0} \%$ of tree yield occurred on fruiting wood that was $<10 \mathrm{~cm}$ long, with shoots longer than $15 \mathrm{~cm}$ contributing $<5 \%$ to yield. We suggest that results from earlier studies regarding the bud abscission process in very long pistachio shoots should be confirmed on shorter shoots, which contribute significantly to yield. Shoots $>30 \mathrm{~cm}$ in length may be important in establishing vegetative buds in a position above the main tree crown for canopy expansion during the following "off" year.
\end{abstract}

Alternate bearing, the occurrence of a high yield "on" year followed by low yield "off" year, is severe in pistachio (Pistacia vera) (Monselise and Goldschmidt, 1982; Stevenson and Shackel, 1998). Pistachio fruit are borne on 1-year-old fruiting wood, while leaves and buds are borne on current year (new) shoots. If a new shoot is subtended by 1-year-old wood with fruit, then the inflorescence buds on the new shoot abscise (Crane and Iwakiri, 1981). Hence, new shoots of "on" trees are of particular interest to researchers, because inflorescence bud abscission on these shoots is the cause of alternate bearing. The physiological mechanisms of the bud abscission process are unknown (Nzima et al., 1997).

In general, vegetative growth in trees is depressed during periods of reproductive growth (Wardlaw, 1990) and one would expect vegetative growth of pistachio to be depressed during "on" years. Several studies (Brown et al., 1995; Picchioni et al., 1997; Rosecrance et al., 1996; Weinbaum et al., 1994) have found at the whole tree level that "on" year trees have depressed vegetative growth of new shoots compared to "off" year trees. However Crane and Al-Shalan (1977) and Crane and Nelson (1972) reported that more growth occurred during the "on" year than during the "off" year at the individual branch level. For instance, the average growth of 25 branches over two alternate bearing cycles in the cultivar 'Bronte' was found to be 21.9 and $7.6 \mathrm{~cm}$ for the "on" and "off" year, respectively. Similar results led to the conclusion that pistachio is enigmatic since "... extension growth of new shoots is depressed during the light crop year instead of the heavy crop year" (Nzima et al., 1997). Hence, there is a discrepancy between whole tree and shoot level studies of vegetative growth in alternate bearing pistachio, indicating either that there are fewer but longer shoots during the "on" year compared to the "off" year, or that the shoots that have been sampled to study

Received for publication 23 Feb. 1999. Accepted for publication 22 Oct. 1999. We wish to thank Richard Rosecrance for sharing his shoot samples, Michelle Benoit for assistance with whole tree sampling, and S\&J Ranch, Madera, Calif., for use of their trees. The cost of publishing this paper was defrayed in part by the payment of page charges. Under postal regulations, this paper therefore must be hereby marked advertisement solely to indicate this fact. alternate bearing at the shoot level have not been representative of the tree as a whole.

The objective of this study was to determine the lengths of entire populations of new and 1-year-old shoots from "on" and "off" pistachio trees, and to determine the relative importance of the fruit borne by 1-year-old shoots of different lengths to the yield and alternate bearing pattern of the tree as a whole. The new shoots of individual "on" and "off" trees in the same year were compared, as were the new shoots of "on" trees compared to the subtending 1-year-old wood, which were the previous year's "off" new shoots. This information was used to ascertain the relative importance of different sized shoots to overall yield, and to determine an appropriate method of sampling representative shoots of different sizes for physiological studies of the bud abscission process in alternate bearing pistachio.

\section{Materials and Methods}

We defined four types of shoots for this study; "on" and "off" new shoots and "on" and "off" 1-year-old shoots (Fig. 1). The "off" new shoots become next years "on" 1-year-old shoots and bear fruit. "Off" 1-year-old wood does not bear fruit because the inflorescence buds have abscised the previous year. Lateral vegetative buds do not abscise and develop typically into branches.

For our study, >19,500 individual shoots from eight pistachio trees were measured. Six of our trees were part of a mineral nutrition study by Rosecrance et al. (1996). These trees were located in a 1972 planting of 'Kerman' pistachio trees on $P$. atlantica rootstock in a commercial orchard in Madera, Calif. For the Rosecrance et al. (1996) study, 21 of 42 selected trees were stripped of fruit during May 1992. This created groups of "on" and "off" trees which would continue to alternate independently in opposite phases in subsequent years without any further experimental manipulation (Stevenson and Shackel, 1998). Sixteen trees were excavated by R. Rosecrance in September 1994, and divided into the categories fine roots, large roots, rootstock, trunk, canopy branches, new shoots, leaves, and fruit. The new 


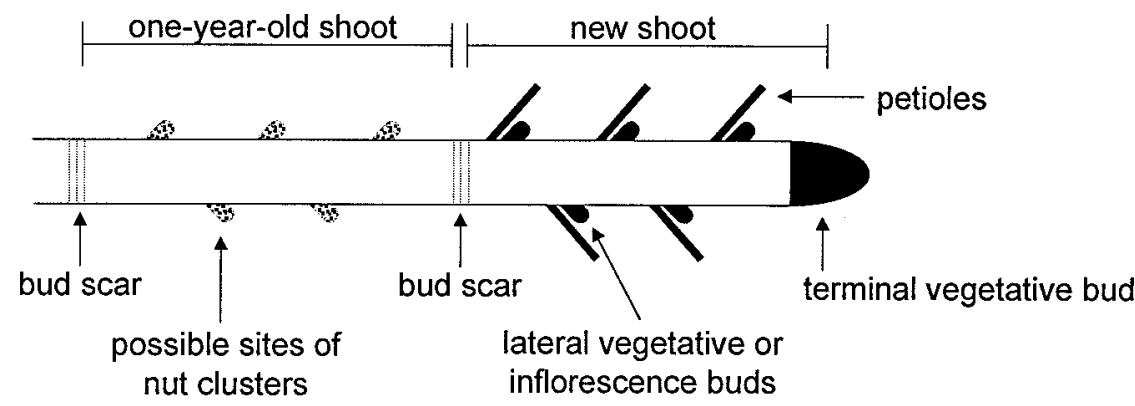

Fig. 1. Schematic representation of shoot morphology in pistachio showing two shoot ages; new and 1-year-old shoots. If fruit are present the shoots are "on", if no fruit are present the shoots are considered "off".

shoot fractions were weighed for a whole tree total. An unspecified sample, probably covering a range of long and short new shoots, were used for mineral nutrient analysis. The remaining new shoots (representing $50 \%$ to $80 \%$ of the total new shoot dry weight) from six of the 16 trees (three "on" and three "off”) were given to us by R. Rosecrance for use in our study. The length of each of these new shoots was measured with an image analysis system (Decagon Devices, Inc., Pullman, Wash.). Two of the six trees, one "on" and one "off", were selected for shoot sampling to determine the relationship between number of retained buds and shoot length. Thirty shoots per tree were selected to represent the entire range of shoot lengths available for those trees, and the number of buds per shoot was counted. Since it is known that the buds which abscise from “on" shoots are inflorescence buds (Crane and Iwakiri, 1981), we assumed that any remaining buds on these shoots were vegetative.

All new shoots, fruiting wood (1-year-old wood), and fruit were harvested individually from one small and one large "on" tree (representing the size range of trees in the orchard) on 26 to 27 Aug. 1996, adjacent to the trees used by Rosecrance et al. (1996). These two trees were naturally "on" and had not been stripped. Every 1year-old and new shoot was removed by cutting and the length of each shoot was measured to the nearest centimeter. All fruit associated with each fruiting wood shoot were weighed, and were also counted on 50 of the fruiting wood shoots per tree. These samples were used to generate a standard curve to convert fruit fresh weight to fruit number. Some fruit were knocked loose from their shoots during removal. These fruit were collected and comprised $<4 \%$ of the tree total yield by weight. All data was analyzed using SAS (1996) regression and general linear models (GLM) software.

\section{Results}

The frequency distributions of "on" and "off" new shoot lengths for the 1994 harvested trees were left skewed (Fig. 2). The mode for "on" trees was $2 \mathrm{~cm}$ and mean length was $5.4 \mathrm{~cm}$, while the mode for "off" trees was $4 \mathrm{~cm}$ and mean length was $5.6 \mathrm{~cm}$. The difference in mean new shoot length between "on" and "off" trees was not significant $(\mathrm{F}=0.05, P=$ $0.84, \mathrm{n}=6$, SAS proc GLM), but both the mode and the mean were greater in "off" trees than in "on" trees. Shoots longer than $\approx 18 \mathrm{~cm}$ represented a small fraction of total shoots in "on" and "off" trees, but such long shoots are quite conspicuous, and there were generally more of these long shoots in "on" compared to "off" trees (Fig. 2 , inset), so that "on" trees may appear to have greater vegetative growth. The length of the current season's "on" new shoot growth for the two trees harvested in 1996, was compared to the attached previous season's "off" growth with a mean \pm SD of $6.2 \pm 8.6 \mathrm{~cm}$ and $4.6 \pm 4.3 \mathrm{~cm}$ for "on" and "off" shoots, respectively. The new shoot length distribution for the trees harvested in 1996 (data not presented) was also similar to that shown for the trees harvested in 1994 (Fig. 2), indicating that the removal of shoots from the 1994 sample, for mineral nutrient analysis, did not influence substantially new shoot length distribution.

Long new shoots in "on" trees are associated typically with long 1-year-old shoots, which may bear very large fruit clusters. There was a clear positive association between the length of 1-year-old shoots, and the length of the attached new shoots, which approximated a 1:1 relation for the "on" trees harvested in 1996 (Fig. 3). 1year-old shoots $<10 \mathrm{~cm}$ bore new shoots that on average were slightly longer than expected based on a 1:1 relation, but because these shoots grew in different years this difference may have been due to differences in growing conditions between years. There was also a significant positive correlation between 1-year-old shoot length and the number of fruit borne on each shoot both for a comparatively large and a comparatively small tree (Fig. 4), although again variation in the number of fruit on shoots of the same length was substantial and the $R^{2}$ for these relationships were low.

Fig. 2. Frequency histogram of new shoot lengths from 3 "on" and 3 "off" trees excavated during 1994 in Madera, Calif. These histograms show only 50\% to $80 \%$ of all shoots for each tree, as the remainder were used for mineral nutrient analysis before the length measurements were taken. Each bar represents the mean frequency for three trees for any given new shoot length class, and error bars are \pm 1 SD. Not shown for clarity are three very long "on" shoots $(42,50$, and $52 \mathrm{~cm})$ and 12 very long "off" shoots $(42,43,43,46,46,46,50,52,55,61$, 61 , and $62 \mathrm{~cm}$ ) representing $<0.2 \%$ of the total number of shoots. Insets show the 18 to $40 \mathrm{~cm}$ length classes at an expanded scale.

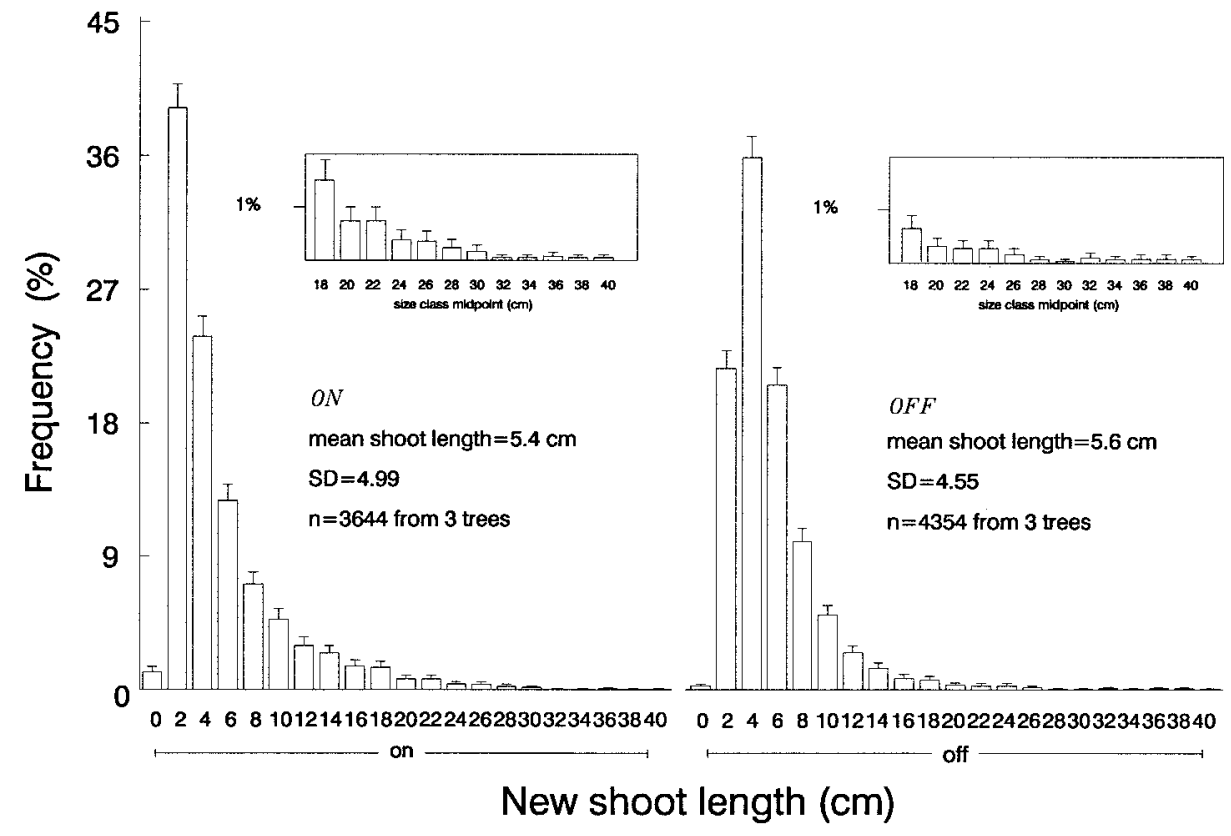




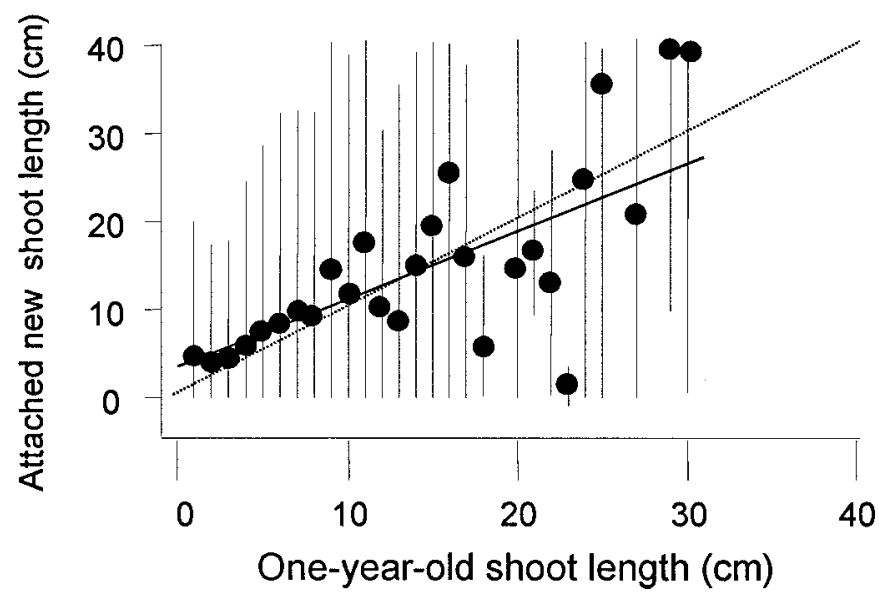

Fig. 3. Relation between the length of 1-year-old shoots and the corresponding length of the attached new shoots for the two trees harvested in 1996. For clarity, only the mean $\pm 1 \mathrm{SD}$ is shown for each one $\mathrm{cm}$ size class of 1-year-old shoot length, and values representing a single observation have been omitted. The regression, fit to all observations, was $\mathrm{y}=0.77 \cdot \mathrm{x}+3.45\left(R^{2}=0.10, \mathrm{~F}=456, P\right.$ $<0.0001)$ displayed by the solid line. The dotted line represents a slope of one. Error bars are cropped at the bottom and top axis.

Despite the positive association of fruit number and 1-year-old shoot length, on a whole tree basis, most fruit were borne by shoots in the 1 to $15 \mathrm{~cm}$ length classes (Fig. 5) and $\approx 95 \%$ of tree yield, accounting for the slight underestimate due to dislodged fruit, was from small fruit clusters located on 1-year-old shoots which were < $15 \mathrm{~cm}$ long on both sizes of tree (Fig. 5 inset).

Both "on" and "off" shoots retain at least one terminal vegetative bud, and additional lateral buds can be either vegetative or floral. In "off" shoots of 2 to $25 \mathrm{~cm}$ length there was a clear positive relation between shoot length and the number of buds retained, whereas "on" shoots of less than $\approx 30 \mathrm{~cm}$ retained only the single terminal bud (Fig. 6). In "on" shoots $>35 \mathrm{~cm}, 8$ to 9 buds were retained (Fig. 6), all of these were near the apical end of the shoot and all were presumably vegetative buds.

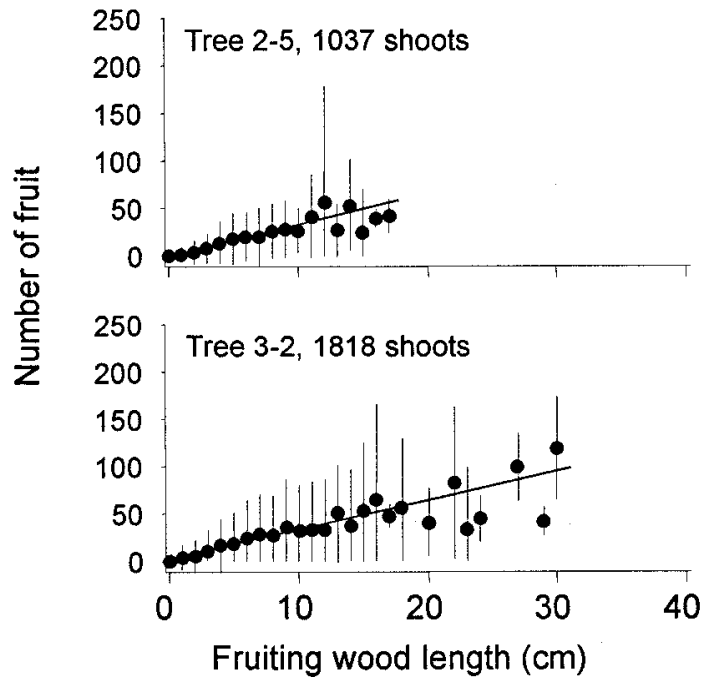

Fig. 4. Relation between the length of 1-year-old shoots and the number of fruit borne on these shoots from two trees harvested in 1996 in Madera, Calif. All new and 1-year-old shoots were sampled from each tree. For clarity, only the mean $\pm 1 \mathrm{SD}$. is shown for each one $\mathrm{cm}$ size class of 1-year-old shoot length. The regression, fit to all data for tree $2-5$ with a total of 1037 shoots was $y=2.78 \cdot x$ $+1.18\left(R^{2}=0.35, \mathrm{~F}=903, P<0.0001\right)$, and for tree $3-2$ with a total of 1818 shoots was $\mathrm{y}=2.19 \cdot \mathrm{x}+5.53\left(R^{2}=0.29, F=1173, P<0.001\right)$.

\section{Discussion}

Several studies of alternate bearing in pistachio have used "on" new shoots on the order of 10 to $20 \mathrm{~cm}$ in length (Crane and AlShalan, 1977; and Crane and Nelson, 1972; Nzima et al., 1997). In these studies shoots were collected to investigate the physiology of alternate bearing at the shoot level, presumably based on the assumption that these results would give insight into the process of alternate bearing at the whole tree level. Concerning the patterns of vegetative shoot growth exhibited by alternate bearing pistachio trees these studies may have been misleading, because they led to the conclusion that shoot growth was increased in "on" years relative to "off" years. Our study has shown that overall shoot growth is similar in "on" and "off" years, but also that there may be somewhat more of the conspicuous, 18 to $30 \mathrm{~cm}$ long shoots in "on" trees. Our results further indicate that shoots $15 \mathrm{~cm}$ and greater in length contribute only $\approx 5 \%$ to total tree yield, and hence we suggest that the behavior of this type of shoot may not be particularly representative of the shoots which contribute the most to overall tree yield.

Many physiological studies seeking to understand the bud abscission process in pistachio have focused on the difference between "on" and "off" trees at the leaf, branch, or shoot level. For instance, Vemmos (1994) tested for differences in leaf photosynthesis, stomatal conductance, chlorophyll concentration, and specific leaf weight that were associated with alternate bearing, but no clear differences were found. Others have investigated hormones as a cause of bud abscission (auxin, Crane and Nelson, 1972; gibberellin, Lin et al., 1984; abscisic acid (ABA), Takeda and Crane, 1980), but found no definitive results. Plant hormones, however, are believed to be closely related to stem elongation (auxins, gibberellins, and cytokinins typically in elongation processes while ABA

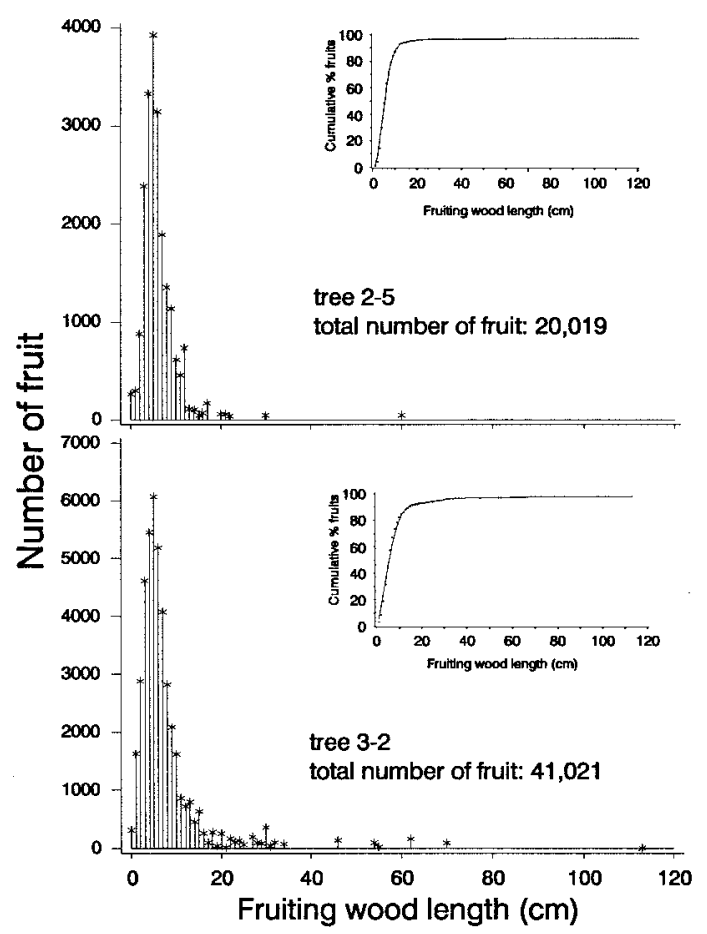

Fig. 5. Histogram of the number of fruit born on each 1-year-old (fruiting) shoot length class from two trees harvested in 1996 in Madera, Calif. Inset histograms show the cumulative percent of total number of fruit per tree, starting with the smallest size class of fruiting wood. Inset histograms only reach $\approx 96 \%$ because some fruit were dislodged from their branches before measurement, therefore, displayed values of cumulative percent fruit are slight underestimates. 


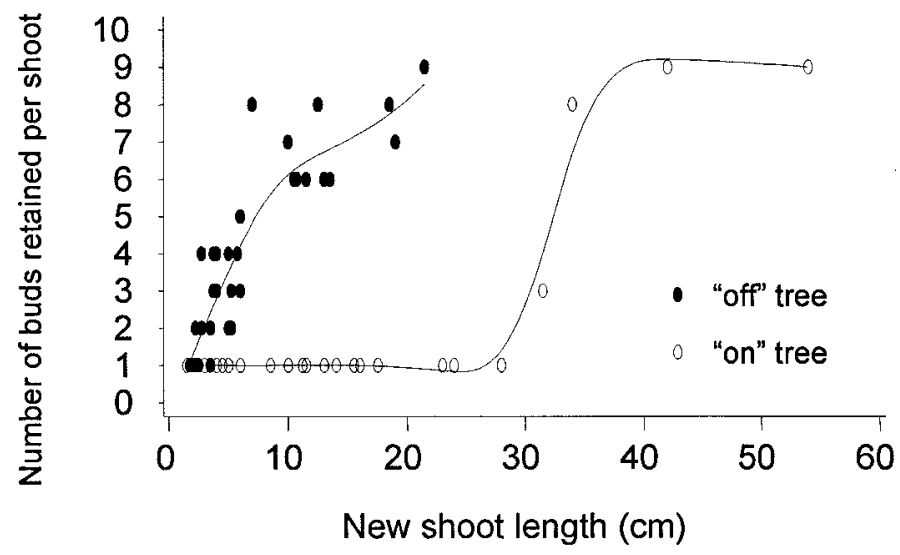

Fig. 6. Relationship between the number of buds retained after abscission and the length of new shoots for two trees excavated in 1994 in Madera, Calif. Solid lines are smoothed splines.

and ethylene usually in elongation inhibition; Taiz and Zeiger, 1991). Therefore, if shoot level studies of alternate bearing pistachio compare long "on" new shoots with short "off" new shoots it may be difficult to separate hormonal effects related to alternate bearing from hormonal effects related to shoot growth. The results of these past physiological studies may need to be confirmed by sampling more short "on" new shoots as well.

If hormone or carbohydrate concentrations are related to the bud abscission process in pistachio as proposed by Wolpert andFerguson (1990), it would be most reasonable to study these processes in shoots representing the size classes contributing the most to overall yield. Future research into the physiology of the bud abscission process in pistachio must recognize that random or systematic sampling (Jessen, 1955) should be used to select shoots representative of the whole tree, and that short "on" shoots must be considered.

Shoots over $15 \mathrm{~cm}$ in length play a minimal role with respect to bearing fruit in "on" pistachio trees, but particularly long shoots over $30 \mathrm{~cm}$ may be important in establishing vegetative buds in a position above the main tree crown for canopy expansion during the following "off" year. For example, the "on" tree in Fig. 6 has many long shoots that have lost their inflorescence buds, while the terminal and subterminal vegetative buds, near the shoot apex, have not abscised. Hence, the shoot growth and bud abscission patterns exhibited by alternate bearing pistachio trees may represent an internally regulated program of canopy development that is consistent with a masting behavior (Stevenson and Shackel, 1998), rather than a localized response of the buds or of the growing shoot to the presence of fruit or the impact that the fruit may have on the availability of carbon or other nutrients.

\section{Literature Cited}

Brown, P.H., S.A. Weinbaum, and G.A. Picchioni. 1995. Alternate bearing influences annual nutrient consumption and the total nutrient content of mature pistachio trees. Trees 9:158-164.

Crane, J.C. and I. Al-Shalan. 1977. Carbohydrate and nitrogen levels in pistachio as related to shoot extension and yield. J. Amer. Soc. Hort. Sci. 102:396-399.

Crane, J.C. and B. Iwakiri. 1981. Morphology and reproduction in pistachio. Hort. Rev. 3:376-393.

Crane, J.C. and M.M. Nelson. 1972. Effects of crop load, girdling, and auxin application on alternate bearing in pistachio. J. Amer. Soc. Hort. Sci. 97:337-339.

Jessen, R.J. 1955. Determining the fruit count on a tree by a randomized branch sampling. Biometrics 11:99-109.

Lin, T.-S., J.C. Crane, and K. Ryugo. 1984. Gibberellin-like substances in pistachio as related to inflorescence bud abscission. HortScience 19:267-268

Monselise, S. and E. Goldschmidt. 1982. Alternate bearing in fruit trees. Hort. Rev. 4:128-173.

Nzima, M., G. Martin, and C. Nishijima. 1997. Leaf development, dry matter accumulation, and distribution within branches of alternatebearing 'Kerman' pistachio trees. J. Amer. Soc. Hort. Sci. 122:31-37.

Picchioni, G.A., P.H. Brown, S.A. Weinbaum, and T.T. Muraoka. 1997. Macronutrient allocation to leaves and fruit of mature, alternatebearing pistachio trees: Magnitude and seasonal patterns at the wholecanopy level. J. Amer. Soc. Hort. Sci. 122:267-274.

Rosecrance, R.C., S.A. Weinbaum, and P.H. Brown. 1996. Assessment of nitrogen, phosphorus, and potassium uptake capacity and root growth in mature alternate bearing pistachio (Pistacia vera L.) trees. Tree Physiol. 16:949-956.

SAS Institute, Inc. 1996. SAS statistics, release 6.12. SAS Inst., Cary, N.C.

Stevenson, M.T. and K.A. Shackel. 1998. Alternate bearing in pistachio as a masting phenomenon: Construction cost of reproduction versus vegetative growth and storage. J. Amer. Soc. Hort. Sci. 123:10691075.

Taiz, L. and E. Zeiger. 1991. Plant Physiology. Benjamin/Cummings Publ. Co., Inc., Redwood City, Calif.

Takeda, F. and J.C. Crane. 1980. Abscisic acid in pistachio as related to inflorescence bud abscission. J. Amer. Soc. Hort. Sci. 105:573-576.

Vemmos, S.N. 1994. Net photosynthesis, stomatal conductance, chlorophyll content and specific leaf weight of pistachio trees (cv. Aegenes) as influenced by fruiting. J. Hort. Sci. 69:775-782.

Wardlaw, I.F. 1990. Tansley review no. 27: The control of carbon partitioning in plants. New Phytol. 116:341-381.

Weinbaum, S., G. Picchioni, T. Muraoka, P. Brown, and L. Ferguson. 1994. Fertilizer nitrogen and boron uptake, storage, and allocation vary during the alternate bearing cycle in pistachio trees. J. Amer. Soc. Hort. Sci. 119:24-31.

Wolpert, J. and L. Ferguson. 1990. Inflorescence bud retention in 'Kerman' pistachio: Effects of defruiting date and branch size. HortScience 25:919-921. 